\title{
Mapping of Vegetation Cover using Segment Based Classification of IKONOS Imagery
}

\author{
Cho, Hyun-Kook, Woo-Kyun Lee ${ }^{1 *}$ and Seung-Ho Lee \\ Korean Forest Research Institute, Cheongryangri-Dong, Dongdaemun-Ku, Seoul 136-012, Korea \\ ${ }^{1}$ Division of Environmental Science and Ecological Engineering, Korea University, Seoul 136-701, Korea
}

\begin{abstract}
This study was performed to prove if the high resolution satellite imagery of IKONOS is suitable for preparing digital vegetation map which is becoming increasingly important in ecological science. Seven classes for forest area and five classes for non-forest area were taken for classification. Three methods, such as the pixel based classification, the segment based classification with majority principle, and the segment based classification with maximum likelihood, were applied to classify IKONOS imagery taken in April 2000. As a whole, the segment based classification shows better performance in classifying the high resolution satellite imagery of IKONOS. Through the comparison of accuracies and kappa values of the above 3 classification methods, the segment based classification with maximum likelihood was proved to be the best suitable for preparing the vegetation map with the help of IKONOS imagery. This is true not only from the viewpoint of accuracy, but also for the purpose of preparing a polygon based vegetation map. On the basis of the segment based classification with the maximum likelihood, a digital vegetation map in which each vegetation class is delimitated in the form of a polygon could be prepared.
\end{abstract}

Key words : Digital vegetation map, IKONOS, Pixel based classification, Segment based classification.

\section{INTRODUCTION}

The classification procedure and method for remote sensed data should be selected considering the quality of the used data as well as the required information. The land cover map which just classifies the imagery into urban, forest, and water could be prepared with the satellite imagery of low resolution. However, a classification to tree species can be made only with the help of high resolution satellite imagery.

Since the commercial high resolution satellite imageries became available for nonmilitary area, their applications have rapidly increased in civil area. It has been widely accepted that higher geometric resolution reduces the proportion of mixed pixels and provides better interpretation possibilities. However the high geometric resolution can also increase the spectral variation within a class and make it difficult to apply the conventional pixel based method (Jensen 1996, Lillesand and Kiefer 2000) for classification.

So called the segment based classification (Mather 1999, Pal et al. 2000, Niemeyer 2001) can provide an alternative method for classifying the high resolution satellite imagery. The segment based classification makes it also possible to delimitate each class in the form of a polygon. So it has been evaluated to be suitable for preparing a polygon based thematic map like the vegetation map.

This study was performed to prove if the high resolution satellite imagery of IKONOS is suitable for preparing the digital vegetation map which gets increasing importance in ecological science. Futhermore this study aims at providing the suitable classification method for preparing the polygon based vegetation map using satellite imagery of IKONOS.

\section{MATERIALS AND METHODS}

\section{Study area and materials}

We used the IKONOS imagery taken in April 2000 in the middle of Kangwon Province which is located in the central eastern Korea (Fig. 1). The IKONOS imagery, which was taken for the area of $11 \mathrm{~km} \times 11 \mathrm{~km}$, is made up of the 4 spectral bands with $4 \mathrm{~m}$ spatial resolution and 1 panchromatic imagery with $1 \mathrm{~m}$ spatial resolution. Multispectral data was fusioned with the panchromatic data using IHS transformation. In the IHS transformation, a band combination of 3-4-1 was selected for the R-G-B color system. The fusioned image was then orthorectified with $\mathrm{PCl}$ OrthoEngine (PCl Geomatics 2001, Cho 2002).

*Author for correspondence; Phone: 82-2-3290-3016, Fax: 82-2-953-0737, e-mail: leewk@korea.ac.kr 


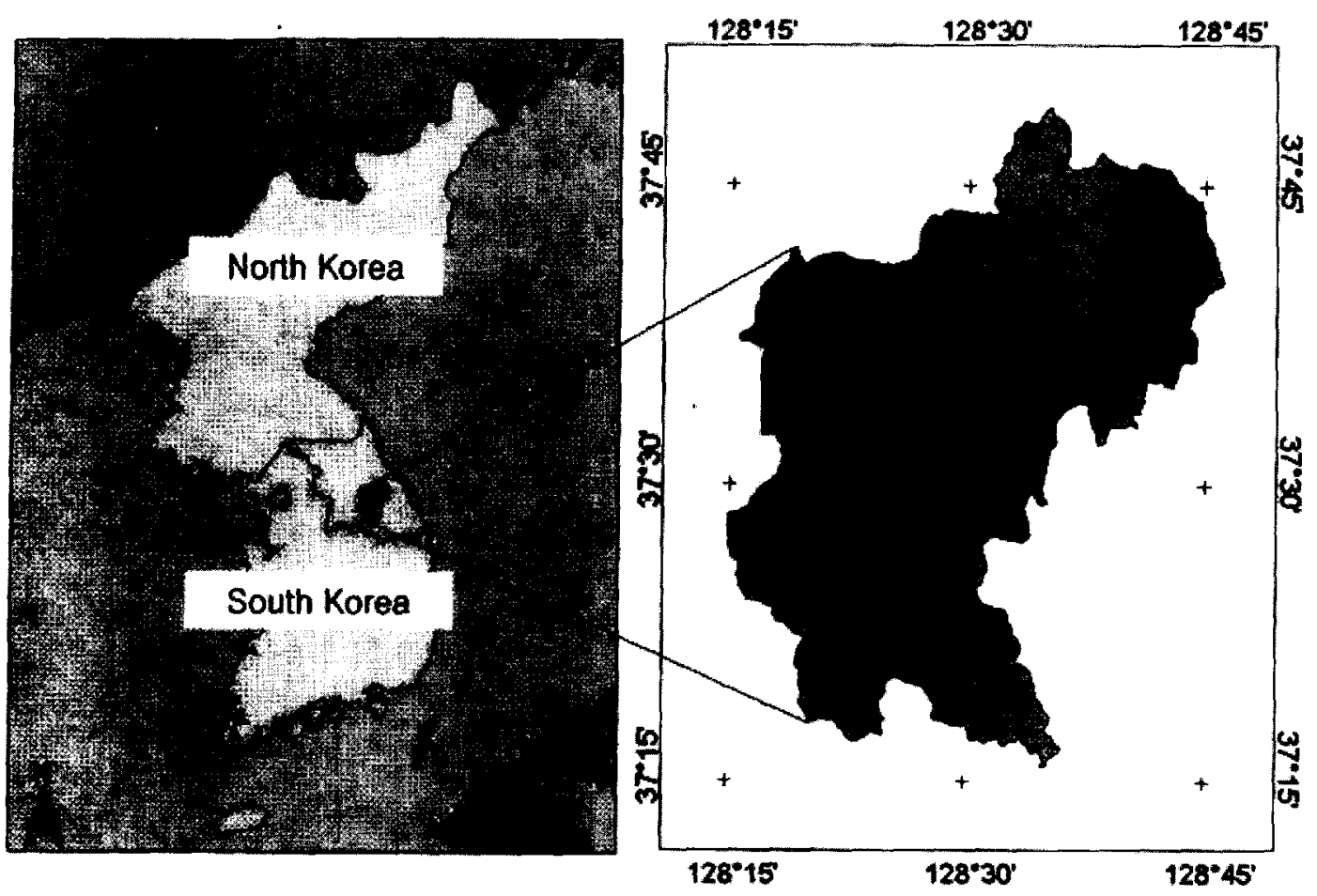

Fig. 1. Study area located in the middle of Kangwon Province.

The terrestrial survey was carried out to set the training area and get the reference data set in the study area. The same training or reference areas were used to compare the results of different classification methods. 260 reference areas (20 areas for each class) were randomly divided into two groups. One group was used for the classification and the other for the verification of the classification.

\section{Classification schema}

A suitable classification schema, in which all required classes are clearly defined, should be introduced for the classification.

Table 1. Classification schema for preparing vegetation map

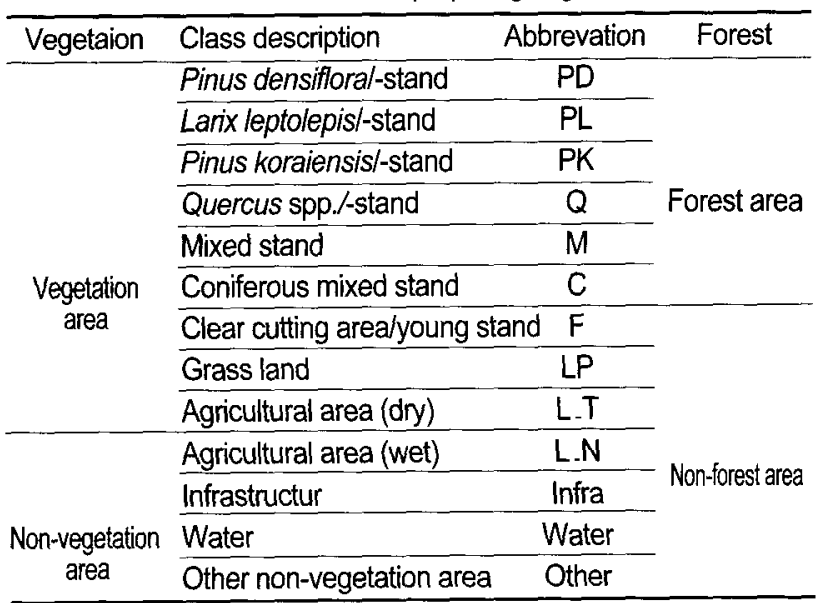

The numbers and types of classes generally depended on the remote sensed data used for classification as well as the required information. We used the high resolution satellite imagery of IIKONOS which can classify the land cover to tree species. The criteria of the forest type map (Korean Forest Research Institute: KFRI 1996) were taken as a basic class for preparing a vegetation map (Table 1).

\section{Classification method}

The classification of the IKONOS imagery was performed using the conventional pixel based method and the new segment based method. The supervised classification method with the maximum likelihood (Jensen 1996, ERDAS 1999, Lillesand and Kiefer 2000) was employed for the pixel based classification.

In the segment based classification (Dulyakarn et al. 1999, Mather 1999, Pal et al. 2000, Niemeyer 2001), the IKONOS imagery was segmented using eCognition which was developed by Definiens Imaging and gives the tools for the segment based classification (Definiens Imaging 2000). And each segment was again classified according to the spectral information of the pixels within the segment (Baatz and Schape 2000). Two methods of the majority principle and the maximum likelihood were applied to the segment based classification. In the segment based classification with the majority principle, pixels of each class which were classified by the pixel based method were counted using the GRID module of Arclnfo (ESRI 1995). And a class which 
occupied a majority in a segment was assigned to the segment class.

In the segment based classification with maximum likelihood, the new segment-specific characteristics, which enable classification of each segment, were first derived. The spectral mean values and theirs standard deviations were employed as the segment-specific characteristics. Mean values and standard deviations for the spectral values of the pixels in each segment were calculated using eCognition. So a new data set of 6 artificial channels ( 3 channels for mean values and 3 channels for standard deviations) could be made for the classification of each segment. The classification using these 6 bands were performed with Imagine (ERDAS 1999).

\section{Verification of classification}

The result of classification was verified with the help of the independent reference data set, and the accuracies of the above three methods were compared. Kappa values (Congalton et al. 1983, Congalton and Mead 1983, Congalton 1991, Stehman, 1996) and error matrix (Janssen and van der Wel 1994, Jensen 1996, Congalton 1998, 1991, Stehman and Czaplewski 1998, Stehman 1999, Lillesand 2000) including producer's, user's, and overall accuracy were used for verifying the classification results and comparing the classification methods.

\section{RESULTS AND DISCUSSION}

\section{Pixel based classification with maximum likelihood}

\section{Signature analysis}

Fig. 2 shows the signature diagram of the various land cover (a) and the forest class (b) from the IKONOS imagery. The second channel (infrared channel) of the IKONOS data shows relatively good spectral differences among classes. However, the third channel (blue in multi-spectral data) has no big spectral differences for distinguishing vegetation classes. Pinus dendiffora stand (PD) and coniferous mixed stand (C), Larix leptolepis stand (PL) and deciduous-coniferous mixed stand (M) seem to be hardly distinguishable. This can be attributed to the complex species compositions of the mixed stands.

\section{Classification and accuracy}

After each pixel of the IKONOS imagery was classified through the maximum likelihood method, the result of the classification was verified with the help of an independent reference data set. The error matrix of the classification is displayed in Table 2. The forest area tends to show lower classification accuracy than the non-forest area. This can be attributed to the similar spectral value among the forest classes as well as the high geometric resolution of the IKONOS imagery. The high geometric resolution can cause the high dispersion of the pixel values and false classification within the same forest class. The stronger fluctuation of the forest surface in comparison to the non-forest area would have served as the reason for the lower accuracy in the forest area.

The coniferous mixed forest (C) shows the lowest producer's accuracy of $10.4 \%$. Many of the coniferous mixed forests were classified into Pinus densiflora (PD) or Larix leptolepis (PL). Mixed stands (M) were also poorly classified with the producer's accuracy of $14.7 \%$. This erroneous classification can be attributed to relatively high spectral variation which is caused by the
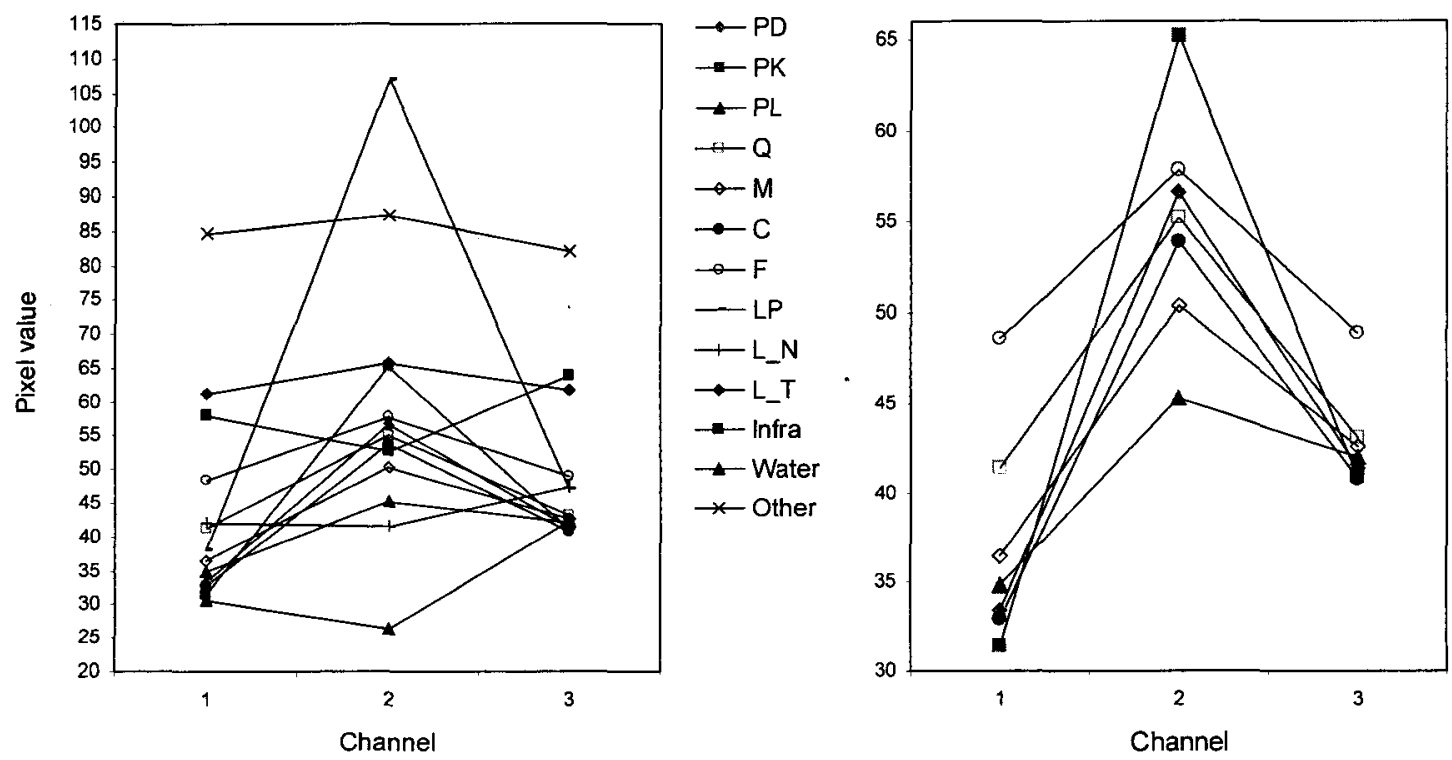

Fig. 2. Average spectral signature of IKONOS imagery for selected training area of various land cover(a)and forest class(b). 
Table 2. Error matrix for the pixel based classification with maximum likelihood

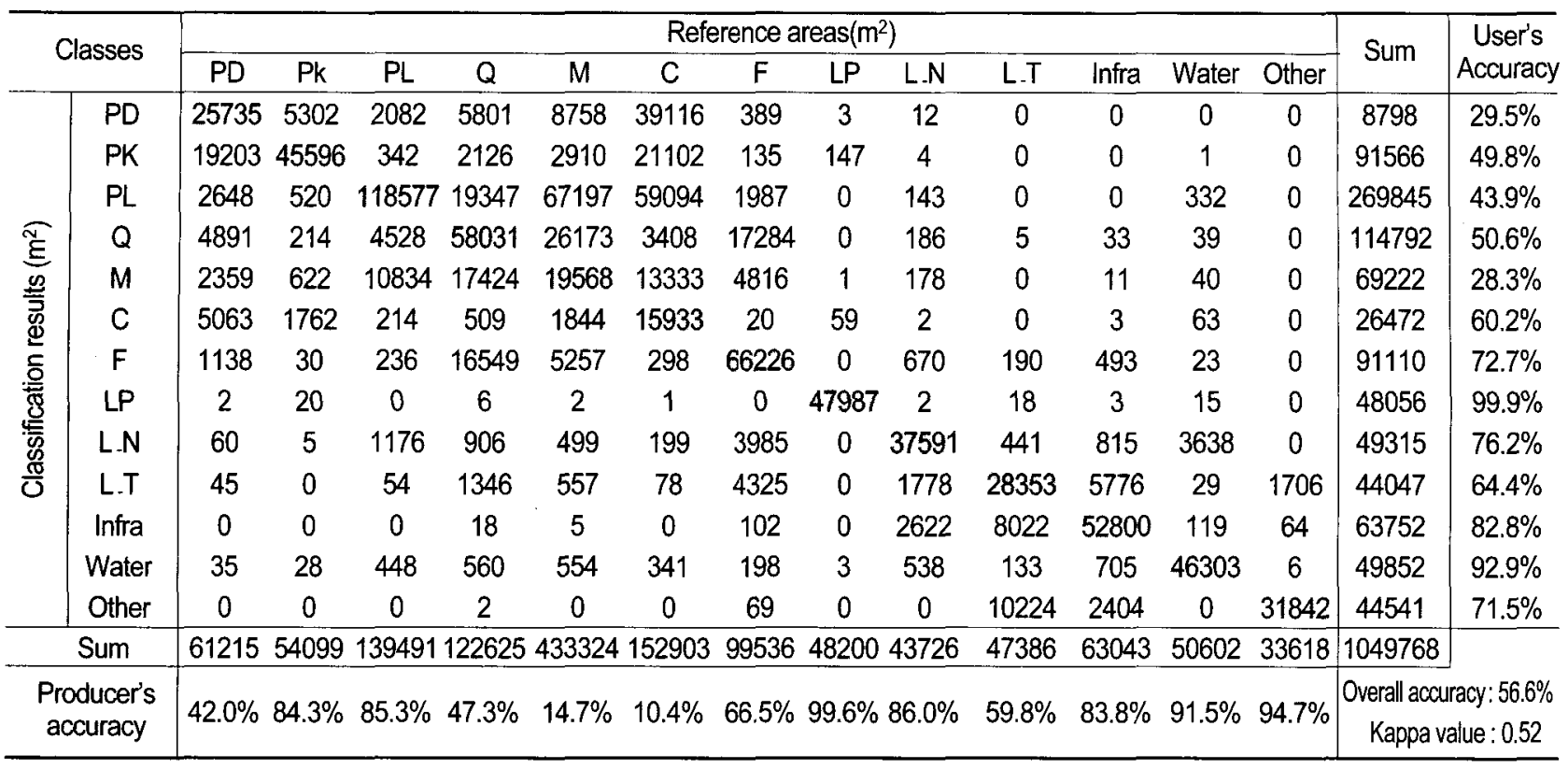

high geometric resolution of IKONOS.

The grass land was classified most accurately with the producer's accuracy of $99.6 \%$. It is notable, however, that some of pixels were falsely classified despite their highly distinguishable spectral value. This might be caused by delimitation error of the reference area.

\section{Segment based classification}

\section{Segment based classification with majority principle}

The error matrix for the segment based classification with the majority principle is shown in Table 3 . Through the segment based classification with majority principle, the overall accuracy could be improved from $56.6 \%$ in the pixel based classification to $65.7 \%$ and the kappa value from 0.52 to 0.62 . While some segments were classified totally into a class and show $100 \%$ accuracy, no segment was classified into mixed forest ( $M$ and $C$ ). The

Table 3. Error matrix for the segment based classification wth majority principle

\begin{tabular}{|c|c|c|c|c|c|c|c|c|c|c|c|c|c|c|c|c|}
\hline \multirow{2}{*}{\multicolumn{2}{|c|}{ Classes }} & \multicolumn{13}{|c|}{ Reference areas $\left(\mathrm{m}^{2}\right)$} & \multirow{2}{*}{ Sum } & \multirow{2}{*}{$\begin{array}{c}\text { User's } \\
\text { Accuracy }\end{array}$} \\
\hline & & PD & $\mathrm{Pk}$ & $\mathrm{PL}$ & $Q$ & $M$ & C & $F$ & LP & L.N & L.T & Infra & Water & Other & & \\
\hline \multirow{13}{*}{ 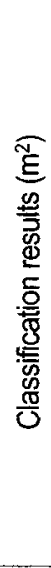 } & PD & 47388 & 0 & 0 & 0 & 0 & 36658 & 0 & 0 & 0 & 0 & 0 & 0 & 0 & 84046 & $56.4 \%$ \\
\hline & PK & 13827 & 54099 & 0 & 0 & 0 & 8027 & 0 & 0 & 0 & 0 & 0 & 0 & 0 & 75953 & $71.2 \%$ \\
\hline & PL & 0 & 0 & 139491 & 35288 & 121328 & 108218 & 0 & 0 & 0 & 0 & 0 & 0 & 0 & 404325 & $34.5 \%$ \\
\hline & $Q$ & 0 & 0 & 0 & 87337 & 11996 & 0 & 0 & 0 & 0 & 0 & 0 & 0 & 0 & 99333 & $87.9 \%$ \\
\hline & $M$ & 0 & 0 & 0 & 0 & 0 & 0 & 0 & 0 & 0 & 0 & 0 & 0 & 0 & 0 & $0.0 \%$ \\
\hline & $\mathrm{C}$ & 0 & 0 & 0 & 0 & 0 & 0 & 0 & 0 & 0 & 0 & 0 & 0 & 0 & 0 & $0.0 \%$ \\
\hline & $F$ & 0 & 0 & 0 & 0 & 0 & 0 & 93458 & 0 & 0 & 0 & 0 & 0 & 0 & 93458 & $100.0 \%$ \\
\hline & LP & 0 & 0 & 0 & 0 & 0 & 0 & 0 & 48200 & 0 & 0 & 0 & 0 & 0 & 48200 & $100.0 \%$ \\
\hline & L.N & 0 & 0 & 0 & 0 & 0 & 0 & 6078 & 0 & 43726 & 0 & 0 & 0 & 0 & 49804 & $87.8 \%$ \\
\hline & L.T & 0 & 0 & 0 & 0 & 0 & 0 & 0 & 0 & 0 & 28838 & 0 & 0 & 0 & 28838 & $100.0 \%$ \\
\hline & Infra & 0 & 0 & 0 & 0 & 0 & 0 & 0 & 0 & 0 & 10263 & 63043 & 0 & 0 & 73306 & $86.0 \%$ \\
\hline & Water & 0 & 0 & 0 & 0 & 0 & 0 & 0 & 0 & 0 & 0 & 0 & 50602 & 0 & 50602 & $100.0 \%$ \\
\hline & Other & 0 & 0 & 0 & 0 & 0 & 0 & 0 & 0 & 0 & 8285 & 0 & 0 & 33618 & 41903 & $80.2 \%$ \\
\hline \multicolumn{2}{|r|}{ Sum } & 61215 & 54099 & 139491 & 122625 & 133324 & 152903 & 99536 & 48200 & 43726 & 47386 & 63043 & 50602 & 33618 & 1049768 & \\
\hline \multicolumn{2}{|c|}{$\begin{array}{l}\text { Producer's } \\
\text { accuracy }\end{array}$} & $77.4 \%$ & $10.0 \%$ & $100.0 \%$ & $71.2 \%$ & $0.0 \%$ & $0.0 \%$ & $93.9 \%$ & 100.0 & $6100.0 \%$ & $60.9 \%$ & $100.0 \%$ & $100.0 \%$ & $100.0 \%$ & \multicolumn{2}{|c|}{$\begin{array}{c}\text { Overall accuracy: } 65.7 \% \\
\text { Kappa value : } 0.62\end{array}$} \\
\hline
\end{tabular}


Table 4. Error matrix for the segment based classification wth maximum likelihood

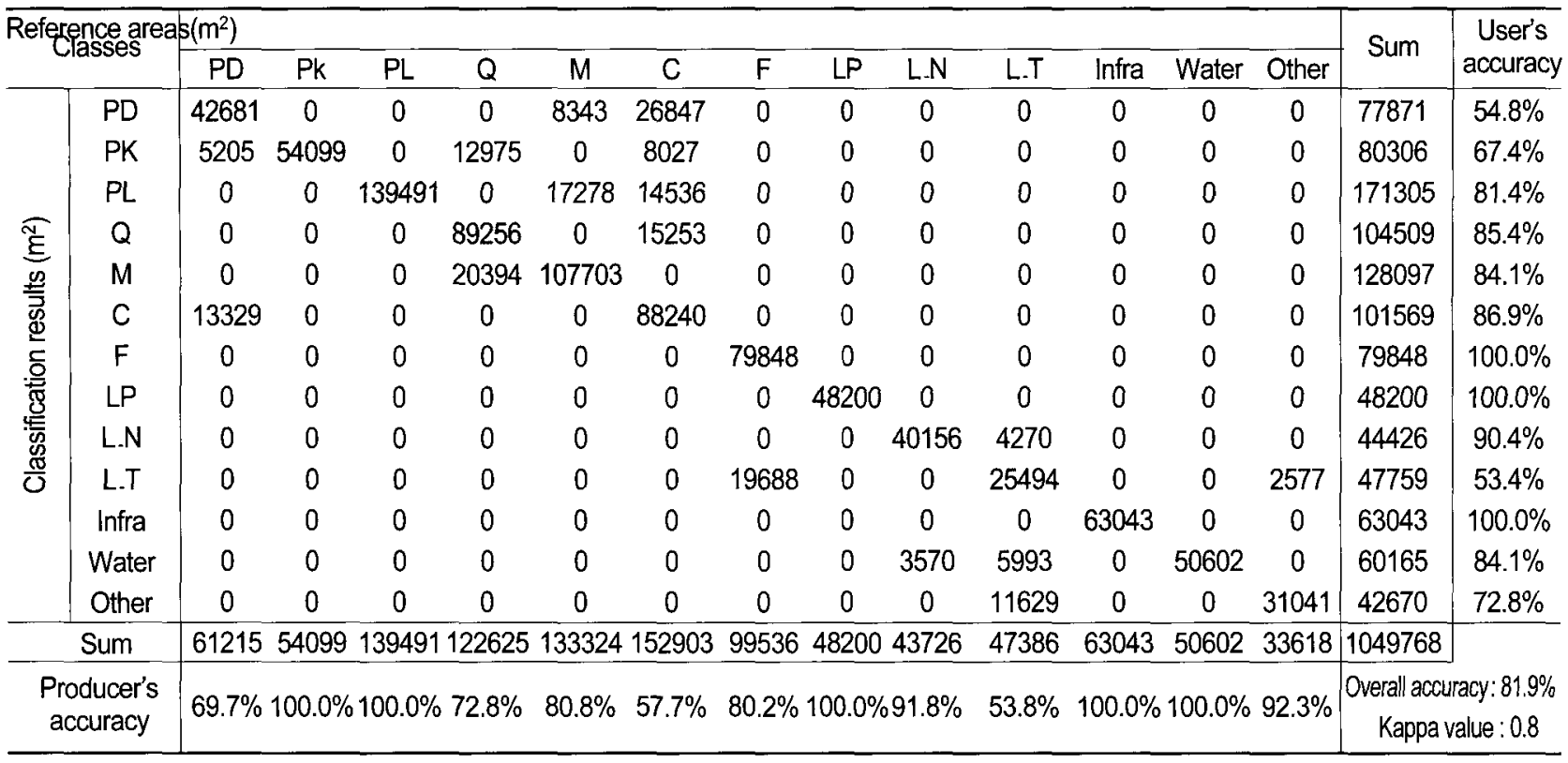

coniferous mixed stands $(C)$ were classified into other coniferous species (PD, PK, PL). And the mixed stands (M) were classified into Larix leptolepis (PL) or Quercus class $(\mathrm{Q})$. This can be caused by the fact that the pixels in each segment were classified into other coniferous or oak class in the pixel based classification (see Table 2). So each pixel doesn't represent mixed stands but just one of the species.

\section{Segment based classification with maximum likelihood method}

\section{1) Signature analysis}

The signature analysis was done in the same training area used in the pixel based classification. The signature diagram for the standard deviation is depicted in Fig. 2. In comparison to the signature for the pixel based classification (Fig. 3), better differences between Pinus densiflora (PD) and coniferous mixed stand $(\mathrm{C})$ as well as between Larix leptolepis (PL) and deciduous mixed stand $(M)$ could be found so that these classes might be better classified.

\section{Classification and accuracy}

The result of verification for the segment based classification with maximum likelihood is shown in form of the error matrix in Table 4. In comparison to the other previous two methods, the segment based classification with the maximum likelihood showed the best performance with the overall accuracy of $81.9 \%$ and kappa value of 0.8 .

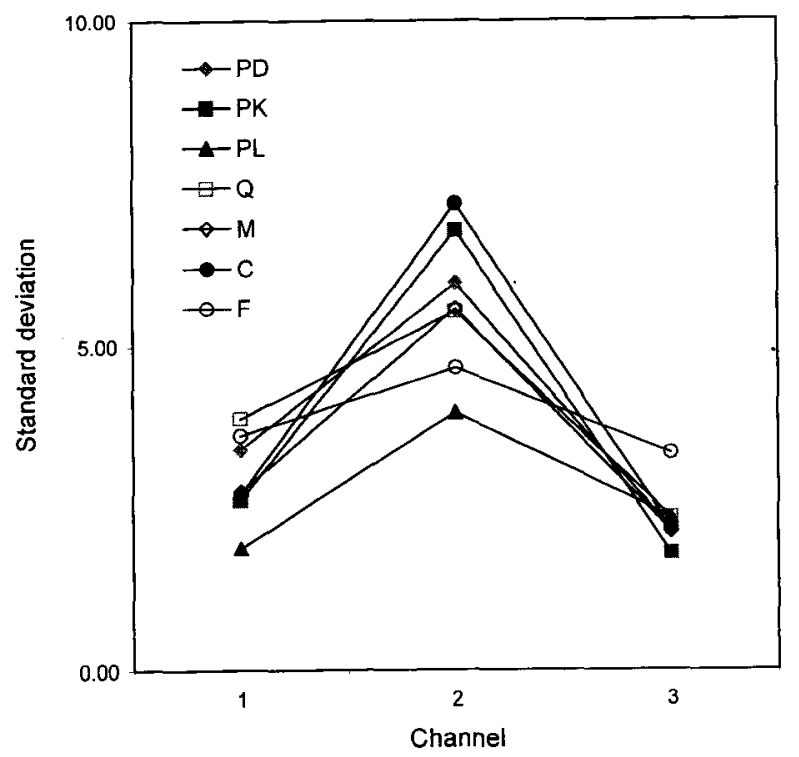

Fig. 3. Mean standard deviation of the IKONOS imagery on segment.

The two mixed forest classes ( $\mathrm{M}$ and $\mathrm{C}$ ), which were hardly classified in the other previous two methods, could be classified with the user' s accuracy of $85.4 \%$ and $84.1 \%$. From the producer's point of view, the coniferous mixed stands could be classified with the producer's accuracy of $57.7 \%$. The lowest accuracy was marked in agricultural dry land $\left(L_{-} T\right)$ with the accuracy of $54 \%$. But through integration of the two agricultural classes into one class, the higher producer's $(76.7 \%)$ and user's accuracy 


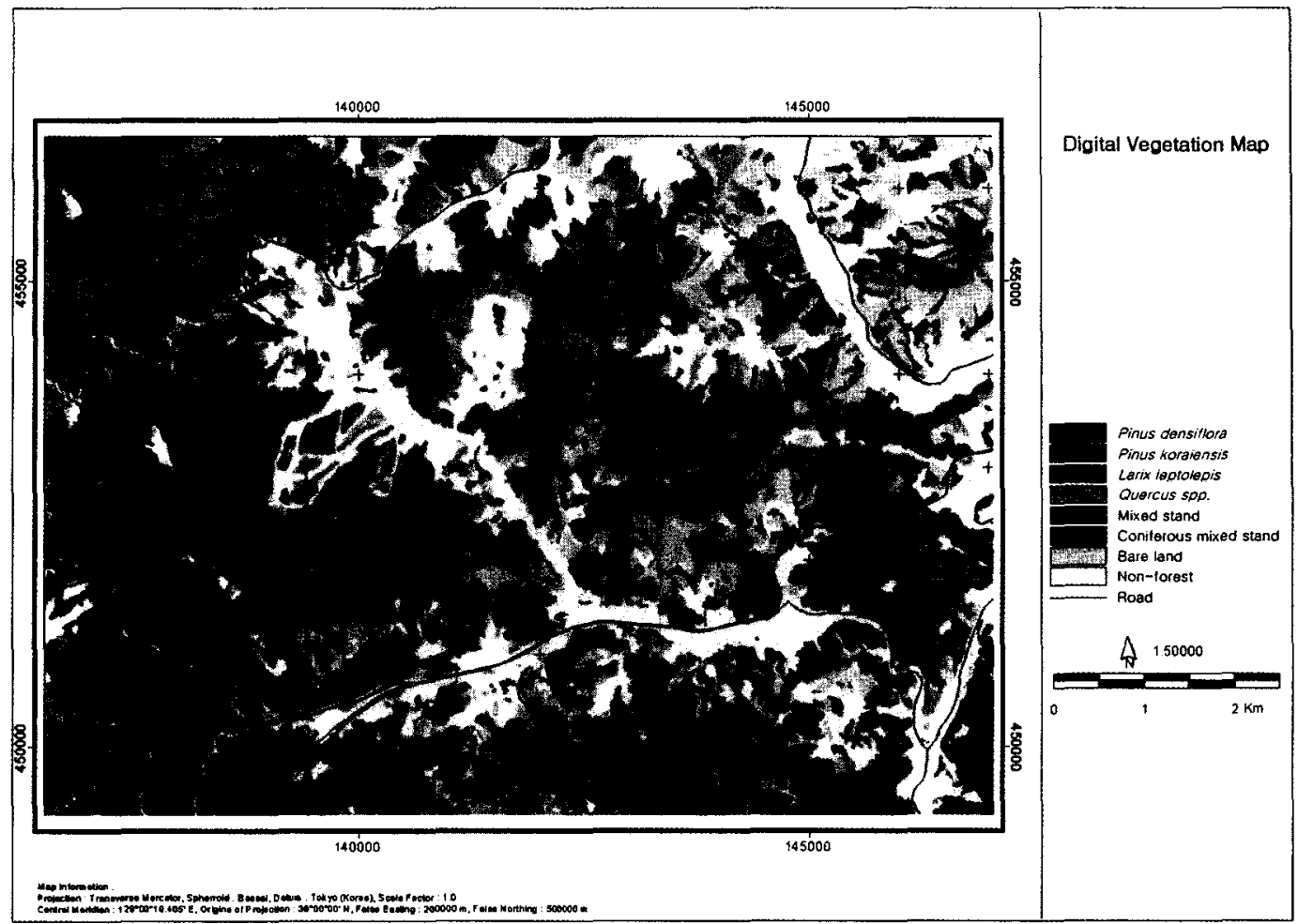

Fig. 4. Digital vegetation map produced from the segement based classification of IKONOS imagery.

(75.8\%) could be obtained.

A good point of the segment based classification with maximum likelihood is that the charactersitics of the segment were newly made on the basis of the spectral information of the segment as well as the pixels in the segment.

\section{Preparation of digital vegetation map}

On the basis of the segment based classification with the maximum likelihood, a digital vegetation map in which each class was delimitated in the form of a polygon could be prepared (Fig. 4).

\section{CONCLUSION}

This study was performed to classify the vegetation type using the high resolution satellite imagery of IKONOS taken in April 2000. Seven classes for forest area and five classes for non-forest area were employed for classification. Three methods, such as the pixel based classification, the segment based classification with the majority principle, and the segment based classification with the maximum likelihood, were applied to classify the IKONOS imagery.

The pixel based classification with the maximum likelihood showed the poorest performance for classifying the vegetation type. The forest area tends to show the lower classification accuracy than the non-forest area. Especially, the mixed forest (C) shows the lowest producer's accuracy.

Through the segment based classification with majority principle, the overall accuracy could be improved from $56.6 \%$ in pixel based classification to $65.7 \%$ and the kappa value from 0.52 to 0.62 .

In comparison to the previous two methods, the segment based classification with the maximum likelihood showed the best performance with the overall accuracy of $81.9 \%$ and kappa value of 0.8 . The two mixed forest classes ( $M$ and $C$ ), which were hardly classified in the previous two methods, could be classified with the user' s accuracy of $85.4 \%$ and $84.1 \%$, respectively.

As a whole, the segment based classification with maximum likelihood was proved to be the best suitable for preparing the vegetation map with the help of the IKONOS imagery. This is true not only from the viewpoint of accuracy, but also for the purpose of preparing a polygon based vegetation map. On the basis of the segment based classification with the maximum likelihood, a digital vegetation map in which each class is delimitated in the form of a polygon could be prepared. 


\section{ACKNOWLEDGEMENTS}

This study is a part of the research (HO323600) supported by KOSEF (Korea Science and Engineering Foundation).

\section{LITERATURE CITED}

Baatz, M. and A. Schape. 2000. Multiresolution Segmentation-an optimization approach for high quality multi-scale image segmentation, Angewandte Geographische Informationsverarbeitung XII, STROBL, J. et al. Beitrage zum AGITSymposium Salzburg 2000, Karlsruhe, Herbert Wichmann Verlag, $p$ 12-23.

Cho, H.K. 2002. Untersuchungen über die Erfassung von Waldflächen und deren Veränderungen mit Hilfe der Satellitenfernerkundung und segmentbasierter Klassifikation. Am Beispiel des Untersuchungsge-bietes "Pyeong-Chang" in Korea. Dissertation, Georg-AugustUniversität Gottingen.

Congalton, R.G., R.G. Oderwald and R.A. Mead. 1983. Assessing landsat classification accuracy using discrete multivariate-analysis statistical techniques. Photogrammetric Engineering \& Remote Sensing, 49:1671-1678.

Congalton, R.G. and R.A. Mead. 1983. A quantitative method to test for consistency and correctness in photointerpretation. Photogrammetric Engineering \& Remote Sensing 49:69-74.

Congalton, R.G. 1988. A comparison of sampling schemes used in generating error matrices for assessing the accuracy of maps generated from remotely sensed data, Photogrammetric Engineering \& Remote Sensing 54(5) 593-600.

Congalton, R.G. 1991. A review of assessing the accuracy of classifications of remotely sensed data. Remote Sensing of Environment 37(1) 35-46.

Definiens Imaging. 2000. eCognition User Guide.

Dulyakarn, P., Y. Rangsanseri and P. Thitimajshima. 1999. Segmentation of Multispectral Images Based on
Multithresholding, Proc. 2nd International Symposium on Operationalization of Remote Sensing, 16-20 August 1999, Enschede, Netherlands, CD-Rom.

ERDAS. 1999. ERDAS Field Guide, 5th Edition. $698 \mathrm{p}$.

ESRI. 1995. Using grid with Arcinfo.

Janssen, L. L. F. und van der Wel, F. J. M. 1994. Accuracy assessment of satellite derived land-cover data: a review. Photogrammetric Engineering \& Remote Sensing, 60(4) 419-426.

Jensen, J.R. 1996. Introductory digital image processing - a remote sensing perspective. Prentice Hall. Upper Saddle River, $318 \mathrm{p}$.

KFRI (Korea Forest Research Institute). 1996. Manual of National Forest Inventory.

Lillesand T.M. and R.W. Kiefer 2000. Remote Sensing and Image Interpretation. John Wiley and Sons, Inc. $724 \mathrm{p}$.

Niemeyer, I. 2001. Satelliten und nukleare Kontrolle. Änderungsdetektion und objektorientierte, wissensbasierte Klassifikation von Multispektralaufnahmen zur Unterstutzung der nuklearen Verifikation, Schriften des Forschungszentrums Julich, Reihe Umwelt / Environment, Band 28. Jülich.

Pal, S. K., A. Ghosh und B.U. Shankar. 2000. Segmentation of remotely sensed images with fuzzy thresholding, and quantitative evaluation. International Journal of Remote Sensing 21:2269-2300.

PCl Geomatics. 2001. OrthoEngine, Geomatica Software solutions.

Stehman, S.V. 1996. Estimating the kappa coefficient and its variance under stratified random sampling. Photogram metric Engineering \& Remote Sensing, 62(4) 401-407.

Stehman, S.V. and R.L. Czaplewski. 1998. Design and analysis for thematic map accuracy assessment: Fundamental principles. Remote Sensing of Environment 64(3) 331344.

Stehman, S.V. 1999. Basic probability sampling designs for thematic map accuracy assessment. International Journal of Remote Sensing 20(12) 2423-2441.

(Received April 8, 2003; Accepted April 22, 2003) 